\title{
PERCEPÇÃO AMBIENTAL DE ALUNOS DA EDUCAÇÃO DE JOVENS E ADULTOS SOBRE O GERENCIAMENTO DE RESÍDUOS SÓLIDOS URBANOS EM HUMAITÁ (AM)
}

Benone Otávio Souza de Oliveira ${ }^{1}$

Vilmara Rocha Graça²

Douglas Marcelo Pinheiro da Silva ${ }^{3}$

Luciano Ferreira Paes ${ }^{4}$

Resumo: Os estudos de percepção ambiental são de grande importância devido à possibilidade de servir como embasamento no planejamento de projetos ou ações voltadas para a educação ambiental. Este trabalho objetivou analisar as percepções de alunos da educação de jovens e adultos sobre o gerenciamento de resíduos sólidos. A metodologia consistiu na aplicação de questionários para diagnosticar suas percepções sobre meio ambiente e resíduos sólidos. Verificou-se que $35 \%$ dos alunos consideram meio ambiente como o lugar que o homem vive. Os alunos reconhecem que parte do problema poderia ser reduzido com mudança de hábitos da população. Foi evidenciado carência de informação dos alunos quanto ao tema resíduos sólidos.

Palavras-chave: Resíduos Sólidos, Percepção Ambiental, Educação Ambiental.

2 Engenheira Ambiental. E-mail: vilmararocha@hotmail.com

${ }^{3}$ Professor do Instituto de Educação, Agricultura e Ambiente- UFAM.. E-mail: dougllasmarcelo@gmail.com

${ }^{4}$ Engenheiro Ambiental. E-mail: ferreirapaes@hotmail.com

Revbea, São Paulo, V. 11, No 1: 284-304, 2016. 


\section{Introdução}

Os problemas referentes à questão dos resíduos sólidos são considerados um dos principais na maioria das cidades. Segundo Giansanti (2009), com a construção do mundo urbano-industrial, os resíduos foram mudando de composição, incorporando aos restos orgânicos novos resíduos, tanto na estrutura dos objetos produzidos quanto nas embalagens. Mudanças que ao longo dos anos se manifestaram na qualidade e na quantidade dos resíduos.

De acordo com Santos e Gonçalves-Dias (2012), assim como outros povos, os brasileiros integram as estatísticas sempre crescentes relativas à produção de resíduos sólidos, apresentando diversos desafios e dilemas para sua gestão. Tais desafios se refletem, principalmente, na disposição final dos resíduos sólidos, pois quando estes são dispostos de maneira inadequada no ambiente, compromete-se o solo, as coberturas vegetais, a água, a atmosfera e consequentemente o próprio homem (GIANSANTI, 2009).

E, somado aos impactos ambientais e sanitários, Santos \& GonçalvesDias (2012) destacam a dimensão sociocultural e antropológica da problemática dos resíduos, devido à existência expressiva de pessoas que extraem dos resíduos sua principal fonte de sobrevivência. Enfim, são muitos os aspectos envolvidos na discussão acerca do gerenciamento de resíduos, fazendo-se necessário também, realizar avaliações críticas sobre as práticas de indivíduos, grupos e setores, bem como uma reflexão sobre as práticas de consumo atuais. Assim, atribui-se à educação ambiental grande importância, pois ela "deve proporcionar aos indivíduos e aos grupos sociais a oportunidade de participarem responsável e eficazmente na prevenção e na solução de problemas ambientais e na gestão da qualidade do meio ambiente" (BRAGA, 2003, p. 23).

Para Dacache (2004), no âmbito escolar é possível aprofundar e levar os alunos a refletir sobre diversas questões que podem ser levantadas explorando o tema resíduos sólidos, desde que este seja tratado de forma interdisciplinar.

Nesse contexto, o estudo da percepção ambiental é considerado estratégia importante, pois, saber o significado que as pessoas atribuem ao meio ambiente torna-se essencial para entender alguns aspectos da relação sociedade-ambiente bem como traçar ações educativas (SALGADO; OLIVEIRA, 2010). Afinal, tentar conhecer a cada um, a partir de seus atos e percepções, pode subsidiar a realização de um trabalho focado em bases locais, propiciando desta forma, atingir resultados mais satisfatórios e adequados à determinada realidade (Carvalho et al., 2012).

No caso da percepção sobre os problemas dos resíduos sólidos, segundo Oliveira (2006),

(...) é preciso que as pessoas, tanto os produtores de lixo como os usuários do meio ambiente, desenvolvam um conhecimento sobre si mesmo. Quer dizer, que conheçam o processo de 
formação, remoção, coleta, tratamento e etc. sobre os resíduos sólidos (lixo), e que este conhecer seja incorporado às ações (p. 48).

Surgiu assim, o interesse em conhecer a maneira como os alunos da Educação de Jovens e Adultos, da Escola Estadual Duque de Caxias, percebem a questão do gerenciamento de resíduos sólidos urbanos em Humaitá-AM, baseado na hipótese de que estes alunos, vindos de diferentes bairros da cidade, percebem os aspectos e etapas de gerenciamento de resíduos de maneira variada, e apresentam uma carência de conhecimentos relacionados a resíduos sólidos de modo geral.

\section{Metodologia}

\section{Local de Estudo}

A Escola Estadual Duque de Caxias localizada na Avenida Transamazônica, Bairro Nova Humaitá, possui mais de 600 alunos matriculados. No período diurno desenvolve atividades no Ensino Fundamental (do $5^{\circ}$ ao $9^{\circ}$ ano) e no turno noturno atende às turmas de Ensino Médio, na modalidade Educação de Jovens e Adultos (EJA).

A escola no Município de Humaitá-AM é a única que atende nesta modalidade de ensino médio, onde são ofertadas 06 turmas com capacidade para receber 40 alunos/sala. A EJA apresenta 06 docentes, dos quais foram pesquisados 04 . No ano letivo de 2014, a escola iniciou suas atividades com 233 alunos matriculados na EJA. Diante deste universo de 233 alunos, adotouse a amostragem aleatória simples, que segundo Gil (1989) consiste em atribuir a cada elemento da população um número único para depois selecionar alguns desses elementos de forma casual. Dessa maneira, a amostra definida neste trabalho compreendeu 60 alunos.

Escolheu-se os alunos da EJA, em virtude da carência de estudos a respeito desse público que demanda das instituições e da sociedade em geral, um novo olhar sobre o processo de educação que vá ao encontro de suas necessidades e especificidades. Além disso, Britto (2010) defende que

Os termos jovens e adultos indicam que, em todas as idades e em todas as épocas da vida, é possível se formar, se desenvolver e constituir conhecimentos, habilidades, competências e valores que transcendam os espaços formais da escolaridade e conduzam à realização de si e ao reconhecimento do outro como sujeito (p. 18). 


\section{Tipos de Pesquisa}

Este estudo teve como abordagem a pesquisa quanti-qualitativa, sendo que para Neves (1996) apud Gomes \& Araújo (s/d), a pesquisa qualitativa é:

(...) um conjunto de diferentes técnicas interpretativas que visam a descrever e decodificar os componentes de um sistema complexo de significados. Tendo por objetivo traduzir e expressar o sentido dos fenômenos do mundo social (p. 06).

A pesquisa quantitativa por sua vez, segundo Fonseca (2002) é centrada na objetividade e

(...) considera que a realidade só pode ser compreendida com base na análise de dados brutos, recolhidos com o auxílio de instrumentos padronizados e neutros. A pesquisa quantitativa recorre à linguagem matemática para descrever as causas de um fenômeno, as relações entre variáveis, etc. (p. 20).

Gomes \& Araújo (s/d) concluem que, apesar da oposição existente entre as duas abordagens (quantitativa e qualitativa) muitos autores, colocam que 0 ideal é a construção de uma metodologia que consiga agrupar aspectos de ambas perspectivas. É o caso de Fonseca (2002), que propõe a utilização conjunta da pesquisa qualitativa e quantitativa, pois permite recolher mais informações do que se poderia conseguir isoladamente.

\section{Técnicas de Coleta}

A coleta de dados baseou-se na aplicação de questionários, constituído por questões fechadas e abertas direcionados aos alunos e aos professores, e entrevista à gestora da escola. Segundo Chaer et al. (2011), o uso de questionários é um importante instrumento na obtenção de informações, garantindo $o$ anonimato e, sendo de fácil manejo na padronização dos dados. Além disso, é bastante viável e pertinente para ser empregada quando se trata de problemas cujos objetos de pesquisa correspondem a questões de cunho empírico, envolvendo opinião, percepção, posicionamento e preferências dos pesquisados.

A entrevista também é uma técnica de coleta de dados bastante utilizada. De acordo com Gil (1989), uma de suas vantagens diz respeito à maior flexibilidade, visto que o "entrevistador pode esclarecer o significado das perguntas e adaptar-se mais facilmente às pessoas e às circunstâncias em que se desenvolve a entrevista" (p. 115).

Neste trabalho, adotou-se a entrevista por pautas, a qual apresenta certo grau de estruturação, sendo baseada nos pontos de interesse explorados pelo 
entrevistador, sem muitas perguntas diretas, porém, o entrevistado pode falar livremente à medida que as pautas são apontadas (GIL, 1989).

\section{Etapas da Pesquisa}

A primeira etapa do projeto de pesquisa dividiu-se em três momentos. $O$ primeiro consistiu na revisão bibliográfica; segundo: contato com a Coordenadoria Regional de Humaitá para averiguar a possibilidade de realização da pesquisa na Escola Estadual Duque de Caxias, e terceiro momento: comunicação e apresentação do projeto de pesquisa à direção da escola.

Diante do consentimento para realização do trabalho, iniciou-se a segunda etapa do projeto referente à entrevista com a gestora; aplicação de questionário direcionado aos professores e aos alunos, no mês de fevereiro de 2014.

O questionário aplicado aos alunos com perguntas abertas e fechadas foi estruturado em quatro grupos de questões: I- Perfil do aluno, com a finalidade de obter uma breve caracterização do aluno que frequenta a EJA; II Meio ambiente, teve a intenção de identificar como os alunos percebem o meio ambiente e seus problemas; III- Resíduos sólidos, buscou obter as percepções, conhecimentos e posicionamentos diante dos RSU; e IV- Ações/expectativas dos alunos em relação à conservação do meio ambiente.

Os questionários destinados aos alunos foram aplicados no mês de fevereiro. O professor responsável em cada turma selecionou 10 números referentes à ordem de chamada, e posteriormente os alunos foram convidados a responder o questionário numa sala reservada.

Os professores da EJA responderam o questionário, para complementar as informações dos alunos $e$ identificar $o$ trabalho com as temáticas ambientais.

A gestora da escola foi entrevistada com a finalidade de obter informações sobre o desenvolvimento de projetos de EA na escola.

A terceira etapa compreendeu a tabulação dos dados para posterior análise e interpretação das informações.

\section{Resultados e Discussões}

\section{Percepção Ambiental de Alunos da EJA sobre o Gerenciamento dos RSU}

\section{Perfil dos alunos}

De acordo com Tomita (2012), os alunos que frequentam a modalidade EJA, em sua maioria são trabalhadores, havendo grande diferença de idade, vivências e expectativas entre os educandos. Através da amostragem foi constatado que $63 \%$ dos alunos são do gênero feminino e $37 \%$ do masculino, concordando com o levantamento realizado pelo IBGE (2014) em parceria com Revbea, São Paulo, V. 11, № 1: 284-304, 2016. 
- Ministério da Educação, que afirmam que mais de $50 \%$ dos alunos frequentadores dos cursos de EJA, são mulheres.

A maioria dos alunos pesquisados, $47 \%$, compreende uma faixa etária de 19 a 30 anos, seguido por alunos de até 18 anos (35\%); outros $13 \%$ estão na faixa de 31 a 40 anos e apenas $05 \%$ dos alunos pertencem à faixa etária de 41 a 50 anos. Porém, nenhum aluno se encontra na faixa acima de 50 anos. Isto mostra uma semelhança com os estudos de Lira \& Ricarte (2009) apud Medeiros \& Tabosa (2011), os quais afirmam ser, a presença considerável de jovens, uma característica comum encontrada nas turmas de EJA em escolas do Brasil. Segundo Sousa \& Cunha (2011), o público jovem, procura essa modalidade de ensino, talvez, principalmente, pela necessidade de um diploma para ingressar em outras áreas do mercado de trabalho ou até mesmo para se manterem no emprego.

A Escola Estadual Duque de Caxias é a única de ensino médio na modalidade EJA, na cidade de Humaitá, sendo assim atende alunos de vários bairros da cidade, sendo que $25 \%$ dos alunos pesquisados são do bairro São Domingos Sávio; 17\% do São Francisco; 14\% do São Cristóvão; 12\% do Nova Humaitá (bairro da escola); $08 \%$ do Nova Esperança e 08\% do Divino Pranto. E o restante divide-se nos outros bairros da cidade, como Santo Antônio, São José, São Sebastião, São Pedro e Nossa Senhora do Carmo, sendo que cada bairro apresenta uma realidade específica.

Arco-Verde (2006) salienta que, compreender o perfil do educando da EJA significa também entendê-lo como um sujeito com diferentes experiências de vida e que em algum momento afastou-se da escola devido a fatores sociais, econômicos, políticos e/ou culturais. Entre esses fatores, pode-se destacar o ingresso prematuro no mundo do trabalho. Assim, em relação à ocupação dos alunos, verificou-se que $78 \%$ deles exercem alguma ocupação, dentre as quais se destacam as atividades de pedreiros, agricultores, pescadores, atendentes de loja, moto-taxistas, etc., e um número considerável de mulheres que afirmaram serem donas de casa (25\%). Ou seja, muitos alunos são obrigados a conciliar trabalho e estudo, refletindo-se numa das principais dificuldades para eles. Apenas $15 \%$ se declararam estudantes. E os outros $7 \%$ não responderam à questão.

Tomita (2012), afirma que os alunos da EJA chegam à escola em condições diferentes de alunos da educação convencional, e relembra que muitos jovens e adultos retornam à escola pela dificuldade de se manterem em um mercado de trabalho competitivo e objetivando melhoras profissionais.

\section{Meio ambiente para os alunos da EJA}

Foi evidenciado contradições nas respostas do questionário, nota-se as dificuldades de comunicação e relacionamento de alguns alunos de EJA. Os alunos mostraram conhecimento prévio, até mesmo referente às experiências vivenciadas sobre os diversos assuntos abordados/discutidos (meio ambiente,

revista brasileira educação ambiental 
resíduos sólidos, problemas ambientais), corroborando com Silva \& Marchetto (2015).

No bloco de questões referentes ao meio ambiente, os alunos responderam de maneira diversa no que se refere ao conceito, com isso as respostas foram agrupadas em cinco categorias. A maioria dos alunos, $35 \%$, apresentou o conceito de meio ambiente associado a um lugar ou espaço. Destacam-se as seguintes afirmações: "é o lugar onde vivemos todos nós, ou seja, onde moramos e convivemos uns com os outros" (Aluno 03); "é o local que vivemos, a cidade que moramos" (Aluno 12). Dessa maneira, verifica-se uma percepção ampla e com grande destaque ao elemento humano e urbano: "é todo o espaço que vivemos, como a casa, ruas e vários outros lugares" (Aluno 14). Corroborando com Salgado e Oliveira (2010), o qual encontraram essa categoria, que foi denominada como "lugar para se viver", e julgam estar relacionado com os aspectos socioculturais, tecnológicos e históricos. Branco (1978) apud Mota (2006), ressalta que meio ambiente não se trata apenas de um lugar no espaço, mas todo o conjunto de condições que afetam a existência, desenvolvimento e bem-estar dos seres vivos.

Uma parte considerável dos alunos, $25 \%$, não conseguiu expressar com clareza seu conceito sobre meio ambiente, por isso foram agrupados na categoria diversos. O aluno 42 afirma que "meio ambiente é as pessoas que poluem a natureza"; enquanto o aluno 06 considera o ambiente como um "projeto pra cuidar de coisas que fazem bem pra nós". No entanto, a primeira resposta indica que o aluno percebe um ambiente degradado pelo homem, enquanto a segunda resposta sugere a noção de benefícios ao homem se houver cuidado com o ambiente.

Outro grupo de alunos correspondente a $20 \%$ agregam em seus conceitos tanto o aspecto humano quanto o natural, sugerindo a ideia de interação entre tais aspectos: "Meio ambiente é um espaço compartilhado por humanos, animais, vegetação, etc." (Aluno 07); "É os rios, ruas, matas, e outras coisas também como aonde nós ficamos, na casa, na escola, etc." (Aluno 28); "É todos os espaços que vivemos, com a fauna e flora" (Aluno 47). Para este grupo de alunos o conceito de ambiente apresenta-se de maneira mais completa ressaltando-se o local de vivência como casa, escola e elementos naturais. Segundo Reigota (1994 apud CASTOLDI et al., 2009), estas representações do ambiente podem ser consideradas do tipo "globalizante", pois indica uma relação ou reciprocidade entre a sociedade e a natureza. Estudos realizados por Freitas e Maia (2009), revelaram que somente 09\% dos alunos da EJA tiveram respostas que se aproximaram do conceito de meio ambiente, compreendendo que fazem parte do mesmo.

$\mathrm{Na}$ categoria natureza foram agrupados todos os conceitos que destacaram somente os aspectos naturais, isto é, $15 \%$ dos alunos: "para mim meio ambiente é rios e florestas" (Aluno 16); "é tudo aquilo que desrespeito com a natureza, matas" (Aluno 02); "meio ambiente é a natureza" (Aluno 29). Quando se considera apenas a natureza, o termo se restringe somente ao sentido biológico, ao ambiente físico, não havendo indícios das interações Revbea, São Paulo, V. 11, № 1: 284-304, 2016. 
sociais, políticas e culturais das sociedades (SAUVÉ, 2005 apud CASTOLDI et al., 2009). Na literatura, costuma-se encontrar que a maioria da população considera meio ambiente como sinônimo de natureza, excluindo-se o homem. No entanto, isso não se confirmou neste trabalho, pois um número significativo de alunos incluiu o homem no ambiente. Para Reigota (1994 apud CASTOLDI et al., 2009) esta é uma representação do meio ambiente denominada "naturalista", onde o homem é apenas observador.

Na concepção de Farias (2006, p.01),

$\mathrm{Na}$ maioria das vezes a expressão meio ambiente tem sido utilizada de forma superficial pela mídia, deixando entender que meio ambiente é a mesma coisa que natureza ou recursos naturais. Isso faz com que a população confunda meio ambiente com a ideia romântica de coisas como a defesa das baleias ou a proteção de orquídeas raras, retirando do assunto toda a carga política ou ideológica.

De acordo com o CONAMA 302/2002, meio ambiente é "o conjunto de condições, leis, influência e interações de ordem física, química, biológica, social, cultural e urbanística, que permite, abriga e rege a vida em todas as suas formas" (p. 465).

Apenas $05 \%$ dos alunos afirmaram não saber o que é meio ambiente. Com isso, cerca de $45 \%$ dos alunos (categoria natural, diversos e não sei) não percebem o local onde vivem como seu meio ambiente, no qual atuam e interagem constantemente. É um resultado considerado bom diante de estudos realizados por Neto e Colessanti (2005), onde 83\% dos alunos não apresentaram conceitos adequados. Ainda assim, é necessário desenvolver atividades de EA para que o indivíduo entenda seu papel de agente e sua responsabilidade pelas modificações no ambiente.

Entre os 04 professores pesquisados, o conceito predominante de meio ambiente também diz respeito ao "espaço onde vivemos" acrescido dos aspectos naturais. Somente um professor revelou possuir uma visão naturalista: "meio ambiente é toda a biodiversidade que nos rodeia". Tais concepções podem influenciar os conceitos formados pelos alunos, positiva ou negativamente.

Ao serem questionados sobre ser parte integrante do meio ambiente, $63 \%$ dos alunos responderam que sim, e justificaram de várias maneiras. Muitos relacionaram às práticas individuais de colaboração com o ambiente: "sim porque eu ajudo a cuida das plantas, árvores e tento ajuda e cuida pro nosso ambiente não fica em risco" (Aluno 37); "sim porque faço minha parte no meio ambiente não jogo lixo no chão e outros" (Aluno 39). As maiorias destes alunos entendem que fazer parte do meio ambiente é cuidar dele, como por exemplo, não jogando resíduos em qualquer lugar. 
Outros afirmaram pertencer ao ambiente porque é um ser vivo e todo ser vivo, assim como outras coisas fazem parte do meio ambiente (Aluno 52); "sim, pois faço parte desse mundo, e acho que tudo que existe faz parte do ambiente" (Aluno 01). Vale destacar também a afirmação do Aluno 08: "sim, porque eu posso ajudar a manter o meio ambiente bom ou ruim". Neste caso, o aluno se considera como um ser ativo no ambiente, cujas práticas podem causar mudanças, percebendo assim que suas ações no meio ambiente, do qual faz parte, podem ter consequências positivas ou negativas. De acordo com Neto \& Colessanti (2005), alguns alunos apresentam em suas respostas uma "relação sentimental, emocional, dimensão importante da educação ambiental e do meio ambiente" (p. 07), como: "sim eu dependo dele a minha família depende dele, a vida não será vida se não cuidarmos do meio ambiente" (Aluno 19); "sim, pois procuro não poluir o ambiente, pois necessitamos dele pra sobreviver" (Aluno 45).

Entre os alunos que não se consideram parte do meio ambiente (15\%), aparecem respostas como: "não, porque eu poluo o meio ambiente, eu jogo lixo na rua"(Aluno 42); "não pois já joguei muito lixo por aí, axo que todos já" (Aluno 57). Em partes, é o reconhecimento de que certas ações podem prejudicar o ambiente, mas revela a percepção de não pertencer ao meio ambiente porque não cuida dele. Verificou-se na maioria das respostas a noção de cuidado para justificar tanto o sim quanto o não. Um percentual elevado (22\%) não respondeu o questionamento.

Considerando a realidade da cidade de Humaitá, foi questionado quais seriam seus principais problemas ambientais. $O$ problema ambiental mais citado pelos alunos refere-se aos resíduos sólidos, $32 \%$, o qual é despejado nas ruas, nos rios e nas valas conforme as seguintes afirmações: "o principal problema é a questão do lixo que é jogado em locais não apropriado e com isso entope os boieros e outros" (Aluno 01); "Tem algumas pessoas que jogam os lixos nas ruas e nos esgotos a ceu aberto" (Aluno 02); "as valas estão cheia de lixo e nos corregos também..." (Aluno 60). Verificou-se que a maioria das respostas atribuíram esta situação aos hábitos da população. Corroborando com Freitas \& Maia (2009), que nos seus estudos com alunos da EJA, 78\% consideraram o "lixo nas ruas" como principal problema ambiental. Santos (2005), também obteve o mesmo resultado, mas acrescenta que, os resíduos só se tornam um problema para as pessoas quando não há coleta, pois o acúmulo de resíduos exala mau cheiro e atrai animais. Ao discutir a percepção sobre os RSU no próximo subtítulo, será possível notar a importância dessa etapa de gerenciamento para a população em geral.

Em seguida, 22\% destacaram os problemas voltados à falta de saneamento básico, principalmente no que se refere ao esgoto à céu aberto. Esta percepção está associada a realidade vivida por muitos alunos, que na ausência de infraestrutura relacionada a saneamento básico na cidade, convivem diariamente com esta problemática. No caso da ausência de saneamento básico em algumas comunidades, de acordo com Vasconcelos e Vilarouca (2011), esta configura-se em uma disposição final errônea para os 
efluentes domésticos, o que ocasiona a presença de esgotos a céu aberto oferecendo riscos devido ao acesso de animais domésticos e à proliferação de vetores, acarretando doenças.

A poluição também foi destacada, compreendendo $18 \%$ das respostas, onde alguns alunos descrevem a poluição dos córregos da cidade, poluição do ar através das queimadas, mas a maioria cita somente o termo "poluição", não especificando quando ao tipo.

A situação presenciada atualmente por muitos deles, é a enchente, o que provavelmente os levou a considerá-la como problema ambiental em $13 \%$ das respostas. Neste caso, destaca-se a resposta do Aluno 06: "A enchente porque a cheia do rio Madeira, tá alagando tudo, as casas, as foças e fica água, lixo e fezes todo junto, facilitando o risco de uma doença". Isto demonstra preocupação por parte do aluno em caso de contaminação das águas causada pela dispersão do resíduos sólidos urbanos e esgoto. O aluno 18 ressalta que "as pessoas não valorizam e não cuidam de sua própria cidade e agora o rio tá enchendo e os lixos estão prejudicando eles mesmos". É uma resposta que culpabiliza a população pelas consequências da enchente. Nos resultados de Castoldi et al. (2009), a enchente foi citada apenas uma vez.

Com uma pequena porcentagem, 06\%, aparece como problema ambiental da cidade o desmatamento. Alguns alunos citaram como problema ambiental: "a grande quantidade de caramujo-africano", "uso inadequado de agrotóxicos", desemprego, "escuridão em algumas partes da cidade", "moradia" e "saúde". Com isso, foram agrupados em Outros, correspondendo a 3\%.

Os professores também foram questionados sobre os principais problemas ambientais da cidade de Humaitá, onde 02 professores apontaram aqueles relacionados aos resíduos sólidos; 01 professor citou "a falta de saneamento básico" e outro docente citou "a falta de conscientização humana" como a base para todos os problemas ambientais da cidade. Trata-se de uma concepção bastante semelhante à dos alunos, onde predominou a problemática dos resíduos, seguido pelo saneamento. Corrobora também com os resultados de Soares (2007), onde os professores afirmaram que o "lixo" e "o esgoto não tratado" são os principais problemas ambientais de seu município.

\section{Percepção sobre resíduos sólidos urbanos}

O bloco III referente à percepção sobre os resíduos sólidos, com o objetivo de comprender os diferentes significados dados aos resíduos sólidos urbanos pelos alunos. De acordo com as respostas mais frenquentes, formaram-se cinco categorias.

A primeira categoria de respostas compreende $35 \%$ dos alunos, os quais consideram os resíduos como resto de alimento ou materiais a serem descartados, ou seja, algo sem utilidade: "lixo é tudo que resta da sua casa, resto de comida e materiais." (Aluno 57); "lixo é algo que não tem valor e 
precisa ser jogado" (Aluno 29); "é algo que não presta. Não serve mais pra usar e joga fora" (Aluno 42). Tais percepções são frequentes, corroborando com Neto e Colessanti (2005); Silva e Marchetto (2015); Cavalcante et al. (2009); Boaventura et al. (2010), onde observaram que a maioria dos alunos associam resíduos a restos que não servem mais para o homem. Nesse contexto, podese destacar a "significação ideológica" do resíduo, dada por Santos (2000 apud SANTOS, 2005), pois "cada indivíduo estabelece critério para o que se deve jogar fora, o que se separa, se exclui e o que não presta” (p.11).

$\mathrm{Na}$ segunda categoria (23\%), os alunos apresentaram conceitos diversos, de certa forma incoerentes com o questionamento: "tira o lixo da rua" (Aluno 21); "para mim o lixo deve está na lixeira" (Aluno 38). Estas respostas reafirmam a carência de conceitos mais amplos a respeito dos aspectos em torno dos resíduos sólidos.

A terceira categoria abrange as respostas que atribuem aos resíduos sólidos sinônimo de sujeira, $20 \%$, conforme as seguintes afirmações: "sujeira que polui o mundo" (Aluno 35); "sujeira, podre, fedorento, imundo" (Aluno 04); "lixo é sujeira, imundice" (Aluno 59). De acordo Moreira e Figueiró (2009), o termo "lixo" apresenta vários e distintos significados, sendo que na maioria das vezes, essa palavra transmite uma sensação de repugnância, sujidade, dentre outros sentimentos desagradáveis. $E$ isto pode ser percebido em boa parte da amostra pesquisada.

$\mathrm{Na}$ quarta categoria, $15 \%$ dos alunos, apresentaram-se significados diferenciados da maioria, ressaltando-se as seguintes concepções: "é $O$ descarte de uns e a sobrevivência de outros" (Aluno 45); "lucro se nós pudesse reciclar" (Aluno 30); "algo que se renova, pois é reciclado e volta pra gente" (Aluno 52). Dentre estes alunos, a percepção do resíduo sólido ultrapassa sujeira e inutilidade, pois envolve a questão social e econômica ao atribuir o significado de "sobrevivência" e "lucro" a partir da possibilidade de venda de materiais recicláveis, servindo como fonte de renda para muitas famílias. Somente esta pequena parcela de alunos não veem os resíduos como algo sem valor, e sim como insumo para alguns, pois tem valor econômico e pode voltar para a cadeia produtiva. Concordando com Neto e Colessanti (2005), que apresentou $15 \%$ dos conceitos correspondentes à conjuntura atual, onde 0 resíduo apresenta valor e utilidade.

Diante da variabilidade de respostas ao significado de resíduo sólido, questionou-se sobre o conhecimento do destino dos resíduos produzidos em suas residências, e $85 \%$ afirmaram saber o destino dos seus resíduos, onde todos responderam "para o lixão". $15 \%$ dos alunos alegaram não saber o destino, sendo que um aluno justificou da seguinte forma: "eu coloco na lixeira para o caminhão do lixo levar, pra onde não sel" (Aluno 12). Ou seja, não fazem ideia de toda a problemática que representa a falta de gerenciamento adequado de resíduos atualmente, principalmente no que se refere ao destino final (NETO; COLESSANTI, 2005). Para muitos, o mais importante é que os resíduos sólidos urbanos gerados diariamente sejam coletados. 
Sobre a localização do lixão municipal, $63 \%$ dos alunos afirmaram saber - local da destinação dos resíduos da cidade. Mas apenas $48 \%$ indicaram o local: "na BR-319"; "na estrada Km 8"; "no Km 4 da BR 319"; "no Km 10"; "no km 13". De acordo com Oliveira (2010), assim como a maioria dos municípios brasileiros, Humaitá destina diariamente seus resíduos sólidos em um lixão a céu aberto localizado no Km 10 à margem esquerda da Rodovia BR 319, sentido Humaitá - Porto Velho (RO). Verificou-se que muitos alunos só sabem que seus resíduos são levados para algum lugar na BR 319 e poucos afirmam com exatidão. Chama atenção o fato que $37 \%$ não sabem a localização do lixão municipal, indicando certa despreocupação com o assunto.

No que diz respeito aos problemas causados pelos resíduos sólidos urbanos, os alunos indicaram principalmente as doenças. Em 51\% das respostas indicaram as doenças como problemas causados pelos RSU: "o lixo pode causar diarreia, feridas, coceira e etc." (Aluno 16); "doenças grave que pode levar a morte" (Aluno 20); "causa doenças grave como a dengue" (Aluno 18). Segundo Pereira e Azevedo (2009), a gestão e o gerenciamento inadequados dos resíduos acarretam impactos não só no ambiente físico, mas à saúde pública através de doenças ocasionadas pela disposição inadequada. Ao indicar a doença como problema ocasionado pelos resíduos, o Aluno 08 relaciona com os vetores: "doenças transmitidas por ratos e baratas". Estes e outros vetores encontram-se entre os principais responsáveis pela transmissão de doenças infectocontagiosas, como febre tifoide, cólera, leptospirose, dengue, entre outras (PEDRINI, 2007). Assim, o aluno percebe que o acúmulo de resíduos favorece a ocorrência de focos de vetores transmissores de doenças.

Outro problema bastante citado em $35 \%$ das respostas foi a poluição, onde alguns alunos enfatizam a poluição da água, do solo e outros a poluição do ar, através da emissão de gases responsáveis por maus odores: "poluição no ar devido o mau cheiro" (Aluno 42). Tais resultados corroborando com Silva e Marchetto (2015).

As enchentes aparecem novamente, em $12 \%$ das respostas, desta vez como consequência do acúmulo de resíduos em bueiros provocando inundação, pois segundo o Aluno 01, "o lixo evita o escoamento da água causando enchente".

Sobre a coleta seletiva, $37 \%$ afirmaram não saber nada sobre coleta seletiva, um valor bastante significativo. Por outro lado, $20 \%$ apresentaram informações referentes à coleta convencional, dentre as quais destacam-se: "coleta seletiva é quando o grupo de trabalhadores que passam todos os dias colhendo o lixo das ruas, para não fica acumulando lixo" (Aluno 37); "o caminhão pega o lixo todos os dias" (Aluno 41); "o que eu sei e já vi é quando eles passam para pegar o lixo eles deixam a metade no chão" (Aluno 05); "é um serviço muito pesado, e muito importante pra cidade e pra população" (Aluno 47). O aluno 45, mesmo confundindo coleta seletiva com a convencional, demonstra preocupação com alguns aspectos da gestão e gerenciamento dos RSU ao dizer que "a coleta na cidade é ruim, pois

revista brasileira educação ambiental 
precisamos que os órgãos competentes tenham mais responsabilidade em dar destino no lixo coletado, não jogando em céu aberto, e a população fazer suas lixeiras e ensacolar o lixo". É visível a correlação que o aluno faz entre as partes envolvidas no gerenciamento dos RSU, destacando a ausência de um destino final mais apropriado aos resíduos e a displicência da população na fase de acondicionamento dos resíduos.

$28 \%$ dos alunos apresentaram em suas respostas ideias de separação de resíduos: "é quando separamos o papel, plástico, metal, vidro e restos de comida e colocamos cada um em um recipiente diferente" (Aluno 10); "alguns materiais são separados e vão para reciclagem" (Aluno 58); "que o lixo deve ser coletado separadamente" (Aluno 15). Tais percepções corroborando com Boaventura et al. (2010). Santos (2005) afirma que uma das alternativas para redução da quantidade de resíduos no seu destino final é a coleta seletiva para a reciclagem. Em seus estudos, $46 \%$ dos alunos responderam de forma inadequada sobre o que é coleta seletiva e apenas $09 \%$ responderam corretamente, como sendo a separação de materiais a serem enviados para a reciclagem.

$07 \%$ apresentaram respostas inadequadas ao questionamento, como exemplo: "coleta seletiva é pessoa que trabalha ou recolhe lixo" (Aluno 46); "parece que é o acumulo de lixo, não sei mais nada" (Aluno 20). E 08\% dos alunos não responderam à questão.

Ao serem indagados sobre a reciclagem, o resultado foi positivo. Todos os entrevistados afirmaram saber o que é reciclagem. Entretanto, ao citar os tipos de materiais que podem ser reciclados, muitos alunos fizeram uma lista de materiais pertencentes à mesma categoria. Os materiais mais citados foram o papel/papelão, as garrafas PET e o plástico. No estudo realizado por Santos (2005), obteve-se resultado semelhante, onde papéis e papelão também foram os mais citados, seguidos por garrafas plásticas PET e plástico. Parte dos alunos demonstrou conhecimento sobre os materiais recicláveis, uma parcela significativa, porém, apresentou os materiais de maneira fragmentada: "papel, plástico, cobre, alumínio e ferro" (Aluno 07), sendo que estes três últimos se enquadram na categoria metal, conforme Junkes (2002). No caso da resposta "garrafas petes e plástico" (Aluno 55), também não se considera a garrafa dentro da categoria plástico. A mesma situação ocorre em "metal e latinha de cerveja" (Aluno 50), levando a crer que existe muita confusão na hora identificar os recicláveis.

Divulga-se muito a reciclagem de papel, garrafas PET e latas de alumínio, talvez por isso tenham sido os mais citados pelos alunos. Conforme Pais (2009), o valor agregado da lata de alumínio é mais alto entre todos os materiais recicláveis e isto faz com que aumente a taxa de reciclagem de alumínio no Brasil.

No que se refere à maneira como os alunos veem a situação dos RSU em Humaitá, as opiniões se dividiram com pequena diferença, mas é importante frisar que nenhum aluno considera a situação ótima. Sendo assim, 
$35 \%$ dos alunos a consideram Regular, justificando que: "o carro não leva tudo" (Aluno 21); "demoram passar, deixam lixo pra trás há lugares que passam de vez em quando" (Aluno 12). Nestes tipos de respostas, o fato de a situação dos RSU ser regular está totalmente relacionado ao processo de coleta dos resíduos, quando o aluno demonstra insatisfação com esse serviço.

Outros, porém, justificam que tanto a população quanto o serviço de coleta não colaboram: "precisa mais desempenho da população e a equipe que recolhe" (Aluno 19). A minoria de alunos afirma que a situação dos RSU é regular por conta das atitudes das pessoas: "nem todo mundo tem a consciência de fazer a sua parte, como colocar o lixo no recipiente" (Aluno 43); "porque muitas pessoas jogam lixo nos córregos ou esgotos, ruas e isso só vai piorando só tem sujeira" (Aluno 59). Somente um aluno citou a atuação da administração municipal em relação à falta de investimento no setor de RSU.

De acordo com Junkes (2002), a coleta dos RSU é feita regularmente na grande maioria dos municípios por caminhões da prefeitura próprios para 0 serviço, ou basculantes, ou ainda, tratores adaptados para o serviço sem qualquer tipo de separação prévia e levado para os lixões a céu aberto próximo às cidades. Realidade semelhante à de Humaitá.

Verificou-se nas respostas uma predominância da insatisfação com o serviço de coleta dos resíduos, mas, dois alunos destacaram a destinação final dos RSU, onde um deles afirma: "é regular porque ele é jogado em céu aberto não tem um lugar próprio pra ser jogado" (Aluno 47). Baseado em visitas in loco no lixão da cidade, Oliveira (2010) observou a inexistência de sistema de controle na disposição final e de controle do fluxo de caminhões que descarregam os resíduos sólidos ao lixão. Além disso, todos os tipos de resíduos, expostos a céu aberto, são por vezes queimados para diminuir o volume; odores desagradáveis e a proliferação de micro e macro vetores também são visíveis.

Um número significativo de alunos considera a situação dos RSU Boa: "porque na minha rua tenho um lugar adequado, e o lixeiro passa todos os dias" (Aluno 29); "porque as pessoas tão fazendo sua parte pondo para que seja recolhido e com isso facilita os trabalhadores da coleta a levar o lixo para que seja deixado para o lixão" (Aluno 46); "porque antes não tinha coleta e hoje tem uma vez ao dia" (Aluno 36). Novamente o processo de coleta nos bairros aparece, mas desta vez, justificando a boa situação dos RSU na cidade.

Os $20 \%$ dos alunos que consideram a situação Ruim foram unânimes em justificar suas respostas através de uma questão cultural da população, que diz respeito ao ato de jogar em qualquer lugar um rejeito, com a intenção de se ver livre deste, conforme Neto e Colessanti (2005). Assim, as respostas foram do tipo: "porque tem muito lixo na cidade jogado pelas pessoas" (Aluno 09); "porque os lixos ficam jogados na calçada e os cachorros rasgam e fica tudo sujo" (Aluno 41); "as pessoas não se preocupa em jogar lixo na rua" (Aluno 38).

Outros $20 \%$ consideram a questão Péssima em virtude da grande quantidade de resíduos espalhados na rua (falta de sensibilização); da

revista brasileira educação ambiental 
precariedade do serviço de coleta (carros e trabalhadores): "nem todos fazem o que é certo ajuntar o lixo e colocar sempre na hora que o carro passa pra pegaIo" (Aluno 05); "só dois trabalhadores não dá conta de colher tanto lixo, como por exemplo, de 42 mil habitantes" (Aluno 07).

Considerando que o Gerenciamento Integrado de Resíduos Sólidos Urbanos - GIRSU pode ser composto por atividades relacionadas às etapas de

geração, acondicionamento, coleta e transporte, reaproveitamento, tratamento e destinação final, verifica-se que os alunos percebem com mais ênfase apenas uma parte dela: a coleta. Pois, enquanto o resíduo não for coletado, causará incômodo à população. E conforme dito inicialmente por Oliveira (2006), a percepção dos resíduos não é sonora, gustativa ou tátil, pois trata-se de um problema visual e olfativo.

\section{Ações/expectativas dos alunos em relação a meio ambiente}

Sobre as ações e/ou expectativas dos alunos em relação ao meio ambiente e aos problemas dos RSU, questionou-se inicialmente o que os alunos consideram que deve ser feito para diminuir os problemas relacionados aos RSU. Através das informações formaram-se quatro categorias de respostas.

Foi observado que $58 \%$, acreditam que os problemas relacionados aos RSU podem ser reduzidos se houver conscientização da população, afirmando que: "as pessoas deve ter consciência de não jogar lixo na rua" (Aluno 41); "mais consciência da população e pensar nas consequências" (Aluno 44); "0 povo ter vergonha na cara e jogar lixo no saco" (Aluno 05); "parar de jogar lixo nas ruas e praça" (Aluno 36). Corroborando assim, com os estudos de percepção ambiental realizados por Vasconcelos \& Vilarouca (2011), os quais indicaram que a problemática maior está na educação da população, que não se conscientiza sobre como a disposição inadequada de resíduos gera problemas ambientais, sanitários, estéticos e de saúde pública.

Por outro lado, Neto e Colessanti (2005), afirmam que diminuir os problemas causados pelos resíduos através da ação de "colocar o lixo no lixo" para a coleta diária, é apenas uma forma que a sociedade encontrou para "limpar sua consciência", no sentido de ter cumprido seu papel se colocando em uma posição cômoda, ignorando os fatores consequentes desta ação.

Outra afirmação que merece ênfase é do Aluno 04: "para de usar sacola de plástico e usar outras coisas que desintegrem em menos tempo". Somente este aluno citou algo que pudesse indicar uma alteração no padrão de consumo da sociedade, dando destaque ao consumo de produtos mais apropriados ambientalmente.

$25 \%$ dos alunos consideram que os problemas podem diminuir se houver investimento por parte da administração pública municipal, como: "o prefeito deve tomar providências, pois assim como nós ele também faz gerar o lixo" (Aluno 03); "tem que ter mais garis e mais responsabilidade do governo" 
(Aluno 33); "ter mais caminhões de lixo" (Aluno 25); "o prefeito deve mandar mais carros de lixo, contratar mais trabalhadores..." (Aluno 42). Novamente a coleta dos resíduos ganha destaque na percepção dos alunos.

Um pequeno grupo de alunos, referente a $10 \%$, atribuiu à reciclagem a maneira de diminuir os problemas relacionados aos RSU. A reciclagem é considerada uma das formas de tratamento dos resíduos, mas segundo Oliveira (2006), há alguns anos atrás, era vista como a solução para o problema. Hoje se sabe que a solução está no GIRSU, assim a reciclagem é apenas uma das formas de trabalhar a questão. A reciclagem trata o resíduo como matéria-prima a ser reaproveitada para fazer novos produtos.

Dentro dos $07 \%$ que afirmam que deve haver participação de todos, destaca-se o comentário do Aluno 45: "um interesse de um todo, população, empresas e prefeitura, não só vendo isso como um simples ganho de dinheiro, porque é um problema de todos". Pode-se associar esse pensamento ao GIRSU, pois segundo Zanta e Ferreira (2004, p.01):

O gerenciamento de resíduos sólidos urbanos deve ser integrado, ou seja, deve englobar etapas articuladas entre si, desde a não geração até a disposição final, com atividades compatíveis com as dos demais sistemas do saneamento ambiental, sendo essencial a participação ativa e cooperativa do primeiro, segundo e terceiro setor, respectivamente, governo, iniciativa privada e sociedade civil organizada.

Ao serem questionados se já haviam realizado alguma ação que contribuísse com a conservação do meio ambiente, a maioria citou atividades relacionadas aos RSU. Os alunos que indicaram atividades relacionadas aos RSU, 67\%, afirmaram as seguintes ações: "junto o lixo direitinho, coloco no saco e amarro a boca do saco e deixo para o lixeiro levar" (Aluno 06); "não jogo lixo no chão" (Aluno 05); "participei de um mutirão de limpeza no meu bairro, faz tempo" (Aluno 43); "Reciclei garrafas petes e latinhas, etc." (Aluno 13). Somente um aluno citou redução dos resíduos gerados em sua casa, etapa inicial e essencial no gerenciamento de resíduos.

Um grupo de alunos, 05\%, afirmou ter realizado orientações sobre conservação do ambiente, através de projetos comunitários ou através de conversas informais com vizinhos a respeito do acondicionamento e horário de deposição do resíduo para coleta. Outros $05 \%$ disseram evitar queimadas, principalmente dos resíduos que produzem.

Alguns alunos, correspondente a $02 \%$, afirmaram ter plantado árvores na cidade para conservar o meio ambiente. E apenas $01 \%$ dos alunos destacou ação voltada ao recurso natural água, com a finalidade de evitar desperdício. 
Destaca-se ainda que, $17 \%$ disseram não ter feito nada, onde se ressalta a resposta do Aluno 35: "nada, eu só faço poluir, taco fogo no sítio". Contudo, é reforçada a necessidade da realização da EA na comunidade escolar. Mas, como ressalta Araújo (1997 apud SANTOS, 2005), a EA não deve ter apenas um caráter informativo, mas deve também buscar desenvolver hábitos, atitudes e comportamentos que possibilitem a formação de uma postura ativa na defesa de um ambiente saudável e do uso racional dos recursos naturais.

Questionou-se ainda se os alunos já haviam participado de algum projeto de EA e o resultado revelou mais do que o esperado: a maioria dos alunos, o equivalente a $68 \%$, afirmou que não; $23 \%$ disseram sim e $09 \%$ afirmaram não saber o que é Educação Ambiental. Entre os que disseram "sim", somente quatro alunos identificaram onde: no trabalho, na escola e numa associação.

Quanto ao interesse dos alunos pela temática ambiental, buscou-se questionar a possibilidade em receber informações relacionadas à preservação e conservação do meio ambiente na escola, e todos os alunos afirmaram que gostariam de receber tais informações. $O$ que se relaciona diretamente com a última pergunta aos alunos: a escola pode contribuir para diminuir os problemas ambientais? Como?

Mais uma vez, os $100 \%$ afirmaram que sim, destacando-se as seguintes concepções: "sim, com informações de forma interativa relacionadas ao meio ambiente" (Aluno 15); "sim, dando palestras pros alunos pra todos ficarem informados sobre o problema" (Aluno 22); "dando palestras sobre o meio ambiente, para os alunos chegarem em casa e passa as informações para outras pessoas" (Aluno 31). A maioria das opiniões sugerem palestras e orientações, e a minoria acredita em trabalho mais prático, que leve o aluno a ter contato com a comunidade para fins de conscientização.

\section{Educação Ambiental na Escola Estadual Duque de Caxias}

De acordo com a entrevista direcionada à gestora da escola, verificou-se uma concepção sobre EA caracterizada pelo entendimento da relação homem $x$ natureza e as consequências dessa relação.

Entre os professores, 01 apresentou concepção semelhante à gestora, pois considera-se que a EA trabalha os problemas derivados da relação homem x natureza. Outro acrescenta em sua resposta: os conhecimentos e competências voltados para a conservação do meio ambiente. Outros 02 professores indicaram todas as alternativas sugeridas pela questão: relação homem x natureza; os problemas derivados da relação homem $x$ natureza; as habilidades, valores e atitudes; e os conhecimentos e competências voltados para a conservação do meio ambiente. Assim, parte dos professores possuem uma concepção mais complexa sobre a atuação da EA. 
Para Layrargues (2003) apud Soares (2007), entender a EA como abordagem dos problemas derivados da relação homem $x$ natureza ainda é uma opinião comum, pois, apesar de a complexidade ambiental envolver múltiplas dimensões, verifica-se que muitos modos de fazer e pensar a EA enfatizam ou absolutizam a dimensão ecológica da crise ambiental.

Entretanto, quando questionados sobre quais dimensões a EA compreende, os docentes revelaram o caráter complexo da temática ambiental ao indicarem todas as alternativas: dimensão social, cultural, ecológica, política, econômica e ideológica.

Quanto à opinião dos docentes sobre o trabalho da questão ambiental nas escolas, 02 afirmaram que o trabalho é eventual, e 02 consideraram que as escolas trabalham raramente.

$\mathrm{Na}$ EJA, os alunos tiveram poucas palestras sobre a questão ambiental em 2013, destacando-se: Riscos de acidentes aéreos provocados por aves, em virtude do acúmulo de resíduos nas proximidades de aeroportos e Qualidade da água, ambos realizados por estudantes e professores da Universidade Federal do Amazonas. Projetos desenvolvidos pelos próprios professores, que envolvam a escola como um todo de forma interdisciplinar não foi citado pela gestora, mas afirmou que os professores da EJA costumam trabalhar temáticas ambientais em sala de aula.

Os docentes declararam que nas disciplinas que ministram, observam frequentemente situações em que podem abordar os conhecimentos relativos à EA. E todos afirmaram ter trabalhado o tema "lixo" em suas disciplinas. Da mesma forma, todos compartilham da opinião que a melhor maneira de se trabalhar conhecimentos relativos à temática ambiental é de forma interdisciplinar, ou seja, envolvendo todas as disciplinas. É o que defende a PNEA. Entretanto, a interdisciplinaridade não foi verificada na EJA. A gestora entende que, de modo geral, as dificuldades em desenvolver projetos de EA na escola estão na resistência por parte de alguns professores e ausência de parceria em relação aos órgãos públicos.

\section{Conclusões}

Diante da análise dos dados sobre a percepção dos alunos da EJA envolvendo principalmente meio ambiente e resíduos sólidos, a maioria demonstra uma representação de meio ambiente como sendo o lugar ou espaço onde o homem vive.

Os alunos da EJA consideram que os principais problemas ambientais da cidade de Humaitá dizem respeito aos resíduos sólidos urbanos.

Todos os alunos afirmaram que a escola pode contribuir com a redução desta problemática, realizando palestras, debates e até mesmo práticas de campo, levando-os a refletir sobre suas ações no ambiente. 
$\mathrm{Na}$ escola são poucas ações em EA voltadas para os estudantes da EJA, sendo repassadas principalmente por meio de palestras, na maioria das vezes superficiais e descontínuas. E nesta modalidade de ensino, segundo a gestora e os professores, as temáticas ambientais são abordadas em sala de aula. Todavia, compartilham da mesma opinião ao considerarem que a EA deve ser abordada de maneira interdisciplinar. No entanto, até o momento não foi realizado nada que possa colocar em prática esta opinião.

Os educadores do turno noturno possuem uma boa concepção a respeito da EA, pois não consideraram somente a dimensão ecológica. Mas, ao conceituar meio ambiente, ainda apareceu uma visão naturalista entre eles.

Os alunos apresentam uma carência de conhecimentos relacionados a resíduos sólidos de modo geral, e percebem os aspectos e etapas de gerenciamento de resíduos de diferentes maneiras, atribuindo importância significativa ao processo de coleta dos RSU, sem refletir questões como a produção dos resíduos, a não geração, consumismo, entre outros.

\section{Referências}

ARCO-VERDE, Y.F.S. (coord.). Diretrizes curriculares da EJA. Secretaria de Estado da Educação. Paraná - Curitiba, 2006.

BOAVENTURA, L.A.S.; MARTINS, L.; MAGALHÃES, A.C.J. Compreensão dos estudantes de quatro turmas de educação para jovens e adultos (EJA), de uma Escola estadual de salvador (Bahia), sobre resíduos sólidos. Candombá Revista Virtual, v. 6, n. 2, p. 110-115, jul. - dez. 2010.

BRAGA, C. Natureza: lição preservar. Manaus: Kintaw Design, 2003.

BRITTO, L.P.L. EJA-Modalidade específica da educação escolar. In: SECRETARIA MUNICIPAL DE EDUCAÇÃO. Caderno de orientações didáticas para EJA-História: etapas complementar e final. São Paulo: SME/DOT, 2010.

CARVALHO, E.K.M.A.; SILVA, M.M.P; CARVALHO, J.R.M. Percepção ambiental dos diferentes atores sociais de Vieirópolis, PB. Qualitas Revista Eletrônica. [S.I]. v.13, n.1, p.1-11. Mai. 2012.

CASTOLDI, R.; BERNARDI, R.; POLINARSKI, C.A. Percepção dos problemas ambientais por alunos do Ensino Médio. Revista Brasileira de Ciência, Tecnologia e Sociedade. [S.I]. v.1, n.1, p.56-80, Jul/Dez, 2009.

CAVALCANTE, L.P.S.; CAVALCANTE, L.S.; MEDEIROS, V.S.; MAIA, J.L.; ALENCAR, L.D. Análise da percepção ambiental e sensibilização de educandos do Ensino fundamental de uma escola pública para realização da coleta Seletiva, Campina Grande - PB. Revista Monografias Ambientais. v.9, n.9, p.2047-2054, 2012.

CHAER, G.; DINIZ, R.R.P.; RIBEIRO, E.A. A técnica do questionário na pesquisa educacional. Evidência, Araxá, v.7, n.7, p.251-266, Jun., 2011. 
CONAMA. Resolução no 302, de 20 de março de 2002. In: BRASIL. Legislação de Direito Ambiental. 3를 ed. São Paulo: Rideel, 2008.

DACACHE, F.M. Uma proposta de Educação Ambiental utilizando o lixo como tema interdisciplinar. Dissertação (Mestrado em Ciência Ambiental) Universidade Federal Fluminense, 2004.

FARIAS, T.Q. O conceito jurídico de meio ambiente. Ambito Jurídico, Rio Grande, IX, n. 35, dez. 2006. Disponível em: $<$ http://www.ambitojuridico.com.br/site/index.php?n link=revista artigosleitura> $>$ Acesso em 05 de março de 2014.

FONSECA, J.J.S. Metodologia da pesquisa científica. Apostila. Fortaleza: UEC, 2002.

FREITAS, J.R.S.R.; MAIA, K.M.P. Um estudo de percepção ambiental entre alunos do Ensino de Jovens e Adultos e $1^{\circ}$ ano do Ensino Médio da Fundação de Ensino de Contagem (FUNEC) - MG. Revista Sinapse Ambiental. [S.I]. v.06, n.2, p.55-77, Dez. 2009.

GIANSANTI, R. Atividades para aulas de Geografia. 1aㅡ ed. São Paulo: Nova Espiral, 2009.

GIL. A.C. Métodos e técnicas de pesquisas sociais. $2^{\underline{a}}$ ed. São Paulo: Atlas, 1989.

GOMES, F.P.; ARAÚJO, R.M. Pesquisa Quanti-qualitativa em Administração: uma visão holística do objeto em estudo. (s/d).

IBGE. Mulheres são maioria em cursos do EJA. Disponível em <http://g1.globo.com/Noticias/Vestibular/0,,MUL1163324604,00MULHERES+SAO+ MAIORIA+EM+CURSOS+DO+EJA.html >. Acesso em 04 de Março de 2014.

JUNKES, M.B. Procedimentos para aproveitamento de resíduos sólidos urbanos em município de pequeno porte. Dissertação (Mestrado em Engenharia de Produção). Programa de Pós-Graduação em Engenharia de Produção. Universidade Federal de Santa Catarina - UFSC. Florianópolis, 2002.

MEDEIROS, L.C.; TABOSA, W.A.F. Percepção Ambiental dos estudantes do Curso Técnico em Alimentos do Proeja no IFRN - Campus Currais Novos. 2011.

MOREIRA, D.P; FIGUEIRÓ, A.M. Diagnóstico da percepção ambiental de uma escola municipal de ensino infantil e fundamental de Fortaleza. Anais... IV Congresso de Pesquisa e Inovação da Rede Norte e Nordeste de Educação Tecnológica de Belém-PA. 2009.

MOTA, S. Introdução à Engenharia Ambiental. 4aㅡ ed. Rio de Janeiro: Associação Brasileira de Engenharia Sanitária e Ambiental, 2006.

NETO, A.T.; COLESSANTI, M.T.M. Lixo: uma palavra, vários olhares. Anais... Simpósio Nacional sobre Geografia, Percepção e Cognição do Meio Ambiente Londrina, 2005. 
OLIVEIRA, B.O.S. Diagnóstico da Geração e Disposição Final dos Resíduos Sólidos Urbanos de Humaitá-AM. Trabalho de Conclusão de Curso (Graduação em Engenharia Ambiental). Instituto de Educação, Agricultura e Ambiente. Universidade Federal do Amazonas, UFAM. Humaitá, 2010.

OLIVEIRA, N.A.S. A percepção dos resíduos sólidos (lixo) de origem domiciliar, no bairro Cajuru-Curitiba/PR: um olhar reflexivo a partir da Educação Ambiental. Dissertação (Mestrado em Geografia). Universidade Federal do Paraná. Curitiba, 2006.

PAIS, J.S.D.O. Usina de triagem e compostagem de resíduos sólidos urbanos domiciliares. Boletim Técnico. Planaltina - DF, julho de 2009.

PEDRINI, A.G. (org.). Metodologias em Educação Ambiental. Petrópolis, RJ: Vozes, 2007.

PEREIRA, S.C.M.; AZEVEDO, M.A. A Percepção dos Resíduos Sólidos na Cidade de Viçosa - MG: Diretrizes para Elaboração do Plano de Educação Ambiental. In: 25 Congresso de Engenharia Sanitária e Ambiental, 2009, Recife. Anais, 2009.

SALGADO, G.N.; OLIVEIRA, H.T. Percepção Ambiental das/os Participantes envolvidos com o Projeto Brotar (Microbacia do Córrego Água Quente, São Carlos/SP) como Subsídio à Educação Ambiental. Rev. eletrônica Mestrado Educ. Ambiental, v. 24, jan/jul. 2010.

SANTOS, M.C.L.; GONÇALVES-DIAS, S.L.F.G. Resíduos Sólidos Urbanos e seus impactos socioambientais. São Paulo: IEE-USP, 2012.

SANTOS, R.N. Colocando o lixo no lugar certo: aplicação de oficina de reciclagem do lixo como atividade prática em Educação Ambiental nas escolas de Aracaju/SE. Monografia (Licenciatura em Ciências Biológicas). Universidade Federal de Sergipe. São Cristóvão, 2005.

SILVA, A.E.; MARCHETTO, M. A Percepção da Educação Ambiental no Ensino de Jovens e Adultos - EJA Escola Estadual Antônio Aggio - São Paulo, Capital. E\&S - Engineering and Science, v.2, n.4, p.102-114, 2015.

SOARES, N.B. Educação ambiental no meio rural: estudo das práticas ambientais da Escola Dario Vitorino Chagas - Comunidade rural do Umbu Cacequi/RS. Monografia (Especialização em Educação Ambiental). Universidade Federal de Santa Maria. Santa Maria, 2007.

SOUSA, K.C.; CUNHA, N.S. Perfil dos alunos de Educação de Jovens e Adultos de Teresina. Universidade Federal do Piauí. 2011.

TOMITA, L.M.S. O desafio do ensino de Geografia na EJA. Anais... 4은 Congresso Internacional de Educação, Pesquisa e Gestão. 2012

VASCONCELOS, A.K.P.; VILAROUCA, J. Avaliação da percepção ambiental dos alunos da EMEIF Dagmar Gentil: estudo de caso. 2011.

ZANTA, V.M.; FERREIRA, C.F.A. Capítulo 1: Gerenciamento de Resíduos Sólidos Urbanos. PROSAB, 2004.

Revbea, São Paulo, V. 11, № 1: 284-304, 2016. 